\title{
Real-world persistence and benefit-risk profile of fingolimod over 36 months in Germany
}

Tjalf Ziemssen, MD, PhD, Michael Lang, MD, Björn Tackenberg, MD, Stephan Schmidt, MD, Holger Albrecht, MD, Luisa Klotz, MD, Judith Haas, MD, Christoph Lassek, MD, C. Anne-Marie Couto, DPhil, John A. Findlay, PhD, and Christian Cornelissen, PhD, on behalf of the PANGAEA study group

Neurol Neuroimmunol Neuroinflamm 2019;6:e548. doi:10.1212/NXI.0000000000000548

\author{
Correspondence \\ Prof. Ziemssen \\ Tjalf.Ziemssen@ \\ uniklinikum-dresden.de
}

\begin{abstract}
Objective

To assess the long-term real-world benefit-risk profile of fingolimod in patients with relapsing MS in Germany.

\section{Methods}

This analysis used data from the noninterventional real-world study, Post-Authorization Noninterventional German sAfety study of GilEnyA (PANGAEA), to assess prospectively the persistence, effectiveness, and safety of fingolimod over 36 months ( \pm 90 days) in Germany. For inclusion in the effectiveness analysis $(n=2,537)$, patients were required to have received fingolimod for the first time in PANGAEA, to have at least 12 months of data, and to have completed each 12 -month follow-up period. For the safety analysis $(n=3,266)$, patients were additionally allowed to have received fingolimod before enrollment.
\end{abstract}

\section{Results}

At baseline, $94.7 \%$ of patients in the effectiveness analysis had received a previous diseasemodifying therapy. After 36 months, $70.4 \%$ of patients were still receiving fingolimod. Over this period, annualized relapse rates decreased to 0.265 (95\% CI: 0.244-0.286) from 1.79 (95\% CI: 1.75-1.83), and mean Expanded Disability Status Scale scores remained stable (mean change from baseline: +0.049 [ $95 \%$ CI: -0.015 to +0.114$]$ ). In total, $16 \%$ of patients had 6-month confirmed disability improvement, $12.5 \%$ had 6 -month confirmed disability worsening, and $52.4 \%$ were free from relapses and 6-month confirmed disability worsening. Adverse events (AEs) and serious AEs were experienced by up to $23.4 \%$ and $3.9 \%$ of patients, respectively, during any of the 12-month follow-up periods. The frequency and nature of AEs were in line with previous findings.

\section{Conclusions}

Using systematically collected data from PANGAEA, this analysis demonstrates the sustained effectiveness, high persistence, and manageable safety profile of fingolimod over 36 months. 


\section{Glossary}

$\mathbf{A E}=$ adverse event $\mathbf{A R R}=$ annualized relapse rate; $\mathbf{D M T}=$ disease-modifying therapy; EDSS $=$ Expanded Disability Status Scale; PANGAEA = Post-Authorization Non-interventional German sAfety study of GilEnyA; RCT = randomized controlled trial; $\mathbf{R M S}=$ relapsing MS; SAE = serious AE; SmPC = summary of product characteristic.

Patients with MS require long-term treatment with diseasemodifying therapies (DMTs) that reduce disease activity. To achieve treatment goals and maximize treatment persistence, efficacy should be coupled with a low burden of therapy including an acceptable safety and tolerability profile and convenience. $^{1-3}$

DMTs are assessed in randomized controlled trials (RCTs) under experimental conditions and in selected populations to generate data for regulatory approval. However, RCTs can have limited validity because outcomes may not be generalizable to clinical practice. ${ }^{4-6}$ Real-world studies complement RCTs by assessing DMTs in heterogeneous populations being treated and monitored in clinical practice ${ }^{7}$; furthermore, they can assess outcomes over a longer period and in a larger population than RCTs to measure the treatment effectiveness duration and identify rare events. ${ }^{1,2}$

Fingolimod (Gilenya, Novartis Pharma AG, Basel, Switzerland) is approved in Europe for second-line use in patients with relapsing MS (RMS) or first-line use in patients with rapidly evolving severe RMS. ${ }^{8}$ This eligible population differs from that in pivotal fingolimod phase 3 RCTs with respect to baseline comorbidities, concomitant medications, disease activity, and previous DMT experience. ${ }^{9-11}$ A large, prospective, 5-year Post-Authorization Non-interventional German sAfety study of GilEnyA (PANGAEA) was initiated to generate real-world data, reassessing the effectiveness and safety of fingolimod in clinical practice. ${ }^{8}$ A published interim analysis from PANGAEA highlighted the favorable benefit-risk profile of fingolimod over 12 months, which was consistent with the pivotal fingolimod RCTs. ${ }^{12}$ Here, we used 36-month follow-up data from PANGAEA to evaluate the long-term benefit-risk profile of fingolimod.

\section{Methods}

\section{Standard protocol approvals, registrations, and patient consents}

An ethics committee provided approval before study initiation and had jurisdiction over the medical director of the study. The study was conducted in accordance with the Declaration of Helsinki. Written informed consent was obtained from all participants to document their data before inclusion in the study.

\section{PANGAEA study design and patient selection}

PANGAEA is an ongoing, multicenter, prospective, noninterventional, observational long-term study. Further details about PANGAEA study design and methodology are provided in the study by Ziemssen et al. ${ }^{12,13}$ To date, PANGAEA has generated the largest real-world homogeneous data set of fingolimod-treated patients with MS. For inclusion in PANGAEA, patients were required to have a diagnosis of RMS, to have been prescribed fingolimod $0.5 \mathrm{mg}$ by their physician as part of routine clinical practice, and to have provided written consent. ${ }^{13}$ Patients were recruited from neurologic centers and practices across Germany between April 2011 and December 2013, with the observational period expected to continue until December 2018. ${ }^{13}$ There were no exclusion criteria, except the contraindications in the European fingolimod summary of product characteristics (SmPC). ${ }^{8}$

For inclusion in the present analyses, patients were required to have at least 12 months ( \pm 90 days) of follow-up data and to be receiving fingolimod at the end of each follow-up period being analyzed ( \pm 90 days). In addition, as part of the analysis of clinical outcomes (effectiveness analysis), patients enrolled in PANGAEA were required to have received fingolimod for the first time in PANGAEA. For safety outcomes (safety analysis), patients were included in the analysis irrespective of whether they received fingolimod for the first time in PANGAEA or in clinical trials before PANGAEA; this ensured that the largest number of patients were included.

\section{Data collection and study outcomes}

At PANGAEA enrollment, baseline characteristics were assessed by the treating neurologist during interviews or through medical examinations. During the 36-month followup period, outcomes were assessed at each visit (month 1 and every 3 months thereafter), and data were recorded in standardized electronic case report forms. Effectiveness outcomes investigated were therapy continuation rates, annualized relapse rates (ARRs), disability outcomes were measured using Expanded Disability Status Scale (EDSS) scores, and proportion of patients free from both relapses and 6-month confirmed disability worsening. For safety outcomes, adverse events (AEs) and serious AEs (SAEs) were classified using the Medical Dictionary for Regulatory Activities. The assessment criteria for AEs were not predefined; physicians were requested to report any undesirable event noted during the observation period. Definitions for effectiveness and safety outcomes have been provided in footnotes of the relevant tables and figures.

Effectiveness and safety outcomes were assessed during the 0-12-month ( \pm 90 days), 12-24-month ( \pm 90 days), 24-36month ( \pm 90 days), and $0-36$-month ( \pm 90 days) follow-up periods. Reasons for study discontinuation were assessed for the entire 36-month follow-up period. 


\section{Statistical analyses}

Data for categorical variables are presented as the number and proportion of cases in each category. For continuous variables, data are summarized using mean values, 95\% CIs, SDs, and medians. For proportions of patients, 95\% CIs were calculated using the exact (Clopper-Pearson) method. ARRs and associated 95\% CIs were analyzed using a negative binomial distribution model and logarithm of the time on study as an offset variable. Data were included in the analysis up to the point of treatment discontinuation. If patient data were missing, or if patients were lost to follow-up, data were taken into consideration up to the point of discontinuation.

\section{Data availability statement}

Patient-level data underlying the findings of the present analysis are pseudoanonymized and are therefore not publicly available. This is in agreement with the consent forms signed by patients. The study protocol is published and freely available. $^{13}$

\section{Results}

\section{Study population and baseline characteristics}

The effectiveness analysis was conducted in patients receiving fingolimod for the first time as part of PANGAEA, in which 3,317 patients were assigned a treatment group, 2,537 patients had at least 12 months of follow-up data, 1,997 patients had up to 24 months of follow-up data, and 1,518 patients had up to 36 months of follow-up data (figure e-1, links.lww.com/ NXI/A98). The safety analysis also included patients who had previously received fingolimod and encompassed 4,190 patients assigned to a treatment group, 3,266 with at least 12 months of follow-up data, 2,596 with up to 24 months of follow-up data, and 2,014 with up to 36 months of follow-up data (figure e-1).

Baseline demographic and clinical characteristics were similar between the effectiveness and safety analysis cohorts (table e-1, links.lww.com/NXI/A99). In particular, $94.7 \%$ of patients in the effectiveness analysis and $93.9 \%$ of patients in the safety analysis had received a previous DMT, with the majority in both cohorts having received interferons ( $47.6 \%$ of patients in the effectiveness analysis and $48.0 \%$ of patients in the safety analysis) or glatiramer acetate $(23.5 \%$ of patients in the effectiveness analysis and $23.0 \%$ of patients in the safety analysis).

\section{Effectiveness outcomes over 36-month follow- up period}

Effectiveness outcomes were analyzed in the population of patients who received fingolimod for the first time in PANGAEA.

In patients with assessable data, after 36 months of follow-up, $70.4 \%$ had continued therapy with fingolimod. The proportion of patients who continued therapy with fingolimod following each of the 12-month periods remained similar, being $88.7 \%$ during the $0-12$-month period, $90.3 \%$ during the $12-24$-month period, and $89.9 \%$ during the $24-36$-month period.

After 36 months of fingolimod treatment, the ARR was reduced to 0.265 (95\% CI: 0.244-0.286) compared with 1.79 (95\% CI: $1.75-1.83)^{12}$ in the 12-month period before PANGAEA enrollment (figure 1A), and $58.2 \%$ of patients (95\% CI: 55.8-60.7) were free from relapses (figure 1B). When data were stratified into 12 -month periods, the effect of fingolimod on the ARR that was observed after 12 months (ARR: 0.386 [95\% CI: 0.360-0.414] $)^{12}$ was sustained over the subsequent 12-24-month (0.292 [95\% CI: 0.266, 0.321]) and 24-36-month (0.218 [95\% CI: 0.192-0.247]) periods, with ARRs numerically decreasing during each period (figure 1A). The proportion of patients who were free from relapses increased numerically in each respective 12 -month period (0-12 months: $71.0 \%$ [95\% CI: 69.2-72.7]; 12-24 months: 77.7\% [95\% CI: 75.8-79.5]; 24-36 months: $83.3 \%$ [95\% CI: 81.3-85.1]; figure 1B).

After 36 months of fingolimod treatment, EDSS scores remained stable from baseline (change in the EDSS score from baseline: +0.049 [ $95 \% \mathrm{CI}:-0.015$ to +0.114 ] f figure 2A), 16.0\% (95\% CI: 14.2-17.9) of patients had 6-month confirmed disability improvement, and $12.5 \%$ (95\% CI: 10.9-14.3) had 6-month confirmed disability worsening (figure $2 \mathrm{~b}$ ). When data were stratified into 12 -month periods, EDSS scores remained stable in the first 12 months of treatment $(+0.103$ [95\% CI: +0.061 to +0.145$])^{12}$ and in the 12-24-month $(-0.031$ [95\% CI: -0.068 to +0.006$])$ and 24-36-month ( -0.022 [95\% CI: -0.063 to +0.018$])$ periods (figure $2 \mathrm{~A}$ ). The proportion of patients with 6-month confirmed disability worsening increased numerically in each respective 12-month period (0-12 months: $3.6 \%$ [95\% CI: 2.9-4.4], 12-24 months: $7.5 \%$ [95\% CI: $6.4-8.8$ ]; 24-36 months: $9.7 \%$ [95\% CI: 8.3-11.4]; figure 2B), but remained numerically lower than the proportion of patients with 6-month confirmed disability improvement during each respective 12-month period (0-12 months: 7.3\% [95\% CI: 6.3-8.4]; 12-24 months: $10.5 \%$ [95\% CI: 9.2-11.9]; $24-36$ months: $11.7 \%$ [95\% CI: 10.1-13.4]; figure 2B).

After 36 months of fingolimod treatment, 52.4\% (95\% CI: 49.9-54.9) of patients were free from relapses and 6-month confirmed disability worsening (figure 3 ). When stratified into 12 -month periods, the proportion of patients free from relapses and 6-month confirmed disability worsening numerically increased over time, being $68.8 \%$ (95\% CI: 67.0-70.6) in the 0-12-month period, ${ }^{12} 72.0 \%$ (95\% CI: 70.0-74.0) in the 12-24-month period, and 76.1\% (95\% CI: 73.9-78.2; figure 3) in the 24-36-month period.

\section{Safety outcomes during fingolimod treatment}

Safety outcomes were analyzed in the overall population of patients who received fingolimod in PANGAEA. This included patients who received fingolimod for the first time in 


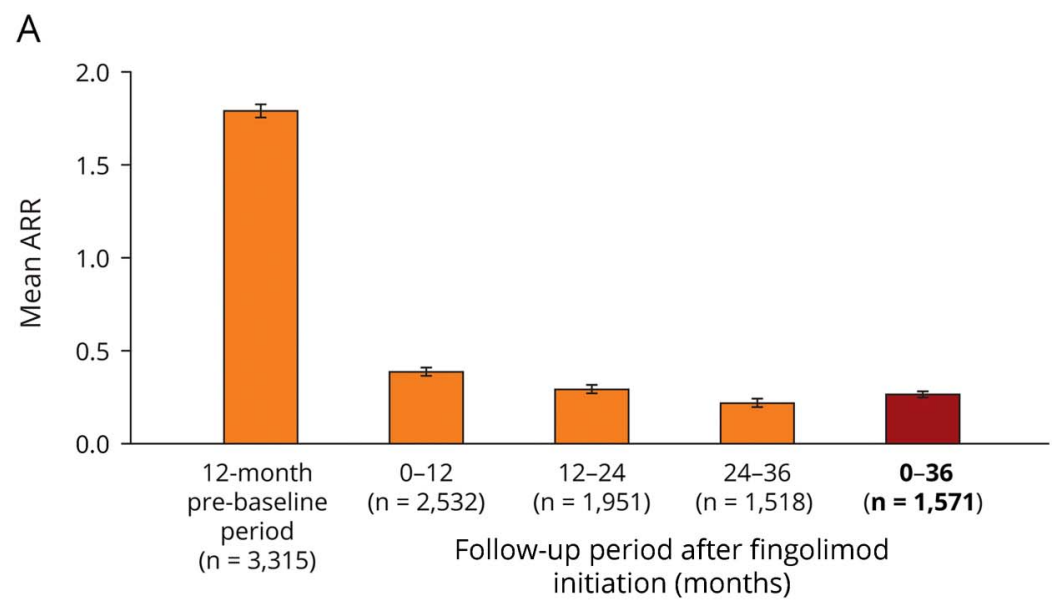

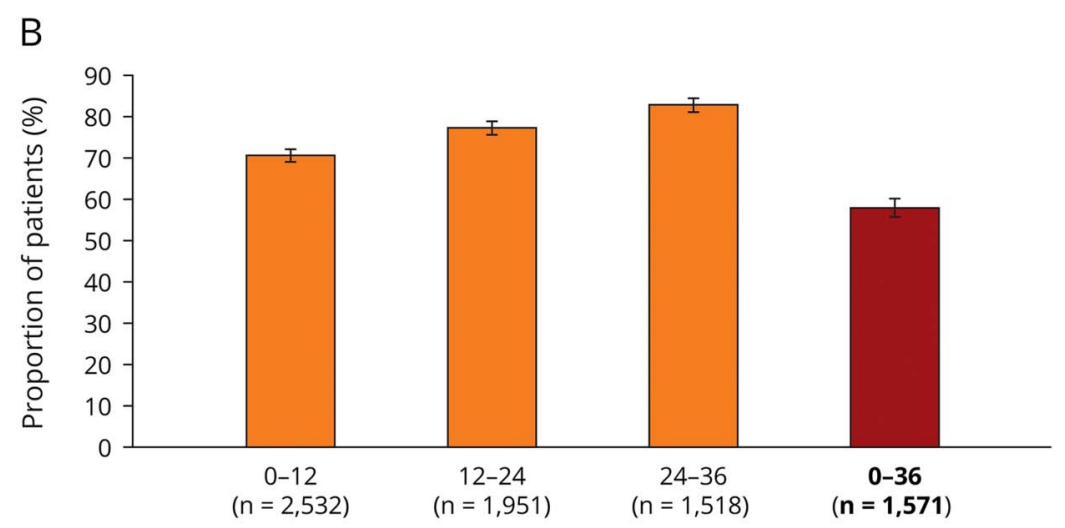

Follow-up period after fingolimod initiation (months)
(A) Mean ARR during the 12-month prebaseline period before fingolimod initiation and during each 12-month follow-up period and in the overall 36-month follow-up period following fingolimod initiation. (B) Proportion of patients with relapse(s) during the 12-month prebaseline period before fingolimod initiation and during each 12month follow-up period and in the overall 36-month follow-up period following fingolimod initiation. ${ }^{a}$ Relapses were assessed in accordance with the clinical judgment of physicians in the real world. Relapses were not included in this analysis if they occurred within 30 days of a previous relapse that had already been included. Error bars show $95 \% \mathrm{Cl}$. ARR = annualized relapse rate; $\mathrm{n}=$ number of patients. Data relating to the ARR for the 12-month prebaseline and 0-12-month periods were taken from Ziemssen T, Lang M, Tackenberg B et al. Clinical and demographic profile of patients receiving fingolimod in clinical practice in Germany and the benefit-risk profile of fingolimod after 1 year of treatment: initial results from the observational, noninterventional study PANGAEA. Neurotherapeutics 2018;15:190-199, with the permission of the copyright holders (authors).
PANGAEA and patients who received fingolimod in previous clinical trials. Data on reasons for premature study discontinuation were available for 1,436 patients. During the 36-month follow-up period, the most frequently reported reasons for study discontinuation were patient decision (27.8\%) and AEs (24.6\%; table 1).

During each 12-month period, the proportion of patients reporting AEs numerically decreased during the 36-month follow-up period, being reported by $23.4 \%, 20.9 \%$, and $20.8 \%$ of patients during the 0-12-, 12-24-, and 24-36-month periods, respectively. The proportion of patients reporting SAEs remained stable during the 36-month follow-up period, being reported by $3.9 \%, 3.9 \%$, and $3.6 \%$ of patients during the 0-12-, 12-24-, and 24-36-month periods, respectively.

The most commonly reported AEs of special interest during the 36-month follow-up period were hypertension, increased hepatic enzyme levels, and increased alanine aminotransferase levels, which were reported by $2.1 \%, 2.0 \%$, and $0.7 \%$ of patients, respectively (table 2 ). The proportion of patients reporting hypertension numerically decreased from $2.2 \%$
(31 patients) during the $0-12$-month period to $1.2 \%$ (11 patients) and $1.0 \%$ (7 patients) during the 12-24- and 24-36month periods, respectively. The proportion of patients reporting other AEs of special interest remained stable during each 12-month follow-up period (table 2).

\section{Discussion}

The population of patients who are eligible to receive DMTs in clinical practice can often differ from those who are enrolled in clinical trials with regard to disease activity, previous DMT experience, comorbidities, and concomitant medications. ${ }^{4}$ Post-approval, real-world studies, such as PANGAEA, therefore provide an important opportunity to reassess the benefit-risk profile of DMTs in the population who receive treatment and are managed in accordance with routine clinical practice. ${ }^{5,13,14}$ Using data collected from PANGAEA over a 36-month period, the present analysis demonstrates that fingolimod is associated with high treatment persistence and sustained clinical effectiveness, coupled with a manageable safety profile in patients with RMS. This analysis contributes 


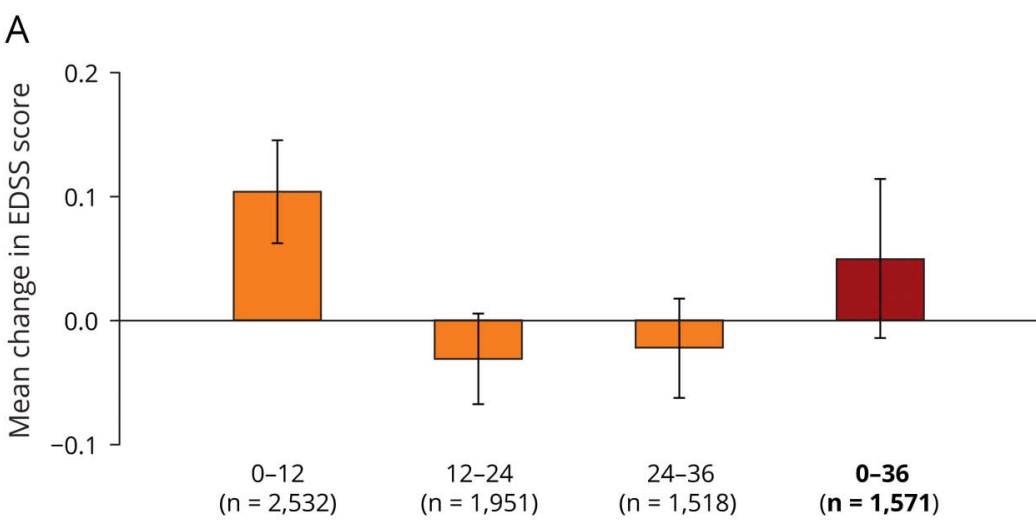

Follow-up period after fingolimod initiation (months)

B

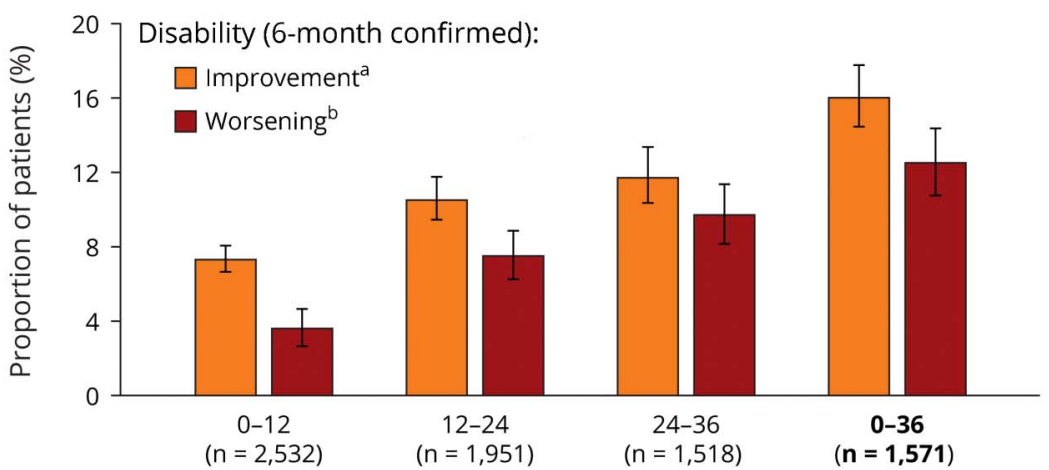

Follow-up period after fingolimod initiation (months)
(A) Mean change in the EDSS score during each 12-month follow-up period and in the overall 36-month follow-up period following fingolimod initiation. (B) Mean proportion of patients with 6-month confirmed disability improvement or 6-month confirmed disability worsening during each 12-month follow-up period and in the overall 36-month follow-up period following fingolimod initiation. ${ }^{a}$ Confirmed disability improvement was assessed in accordance with the decreases in the EDSS score from baseline, with confirmation of the decrease in disability made at a visit in the absence of a relapse: a decrease of at least 1 point regardless of baseline EDSS scores. ${ }^{b}$ Confirmed disability worsening was assessed in accordance with the increases in EDSS score from baseline, with confirmation of the increase in disability made at a visit in the absence of a relapse: a 1.5-point increase from a baseline EDSS score of 0 ; a 1-point increase from baseline EDSS scores of 1-5.0; and a 0.5-point increase in baseline EDSS scores of 5.5 or more. Patients for whom MS was a cause of death were considered to have confirmed disability worsening irrespective of baseline EDSS score or change in the EDSS score. Error bars show 95\% $\mathrm{Cl}$. EDSS = Expanded Disability Status Scale; $\mathrm{n}=$ number of patients. Data for the 0-12-month change in the EDSS score were taken from Ziemssen T, Lang M, Tackenberg B et al. Clinical and demographic profile of patients receiving fingolimod in clinical practice in Germany and the benefit-risk profile of fingolimod after 1 year of treatment: initial results from the observational, noninterventional study PANGAEA. Neurotherapeutics 2018; 15:190-199, with the permission of the copyright holders (authors). to the growing body of evidence for fingolimod $0.5 \mathrm{mg}$ by presenting its benefit-risk profile over a longer follow-up period than that of the core period of the pivotal RCTs (conducted over 12 or 24 months) $)^{9-11}$ or in most other realworld studies. ${ }^{15}$
The present analysis further complements data from the pivotal phase 3 RCTs by evaluating outcomes in patients who received fingolimod in accordance with the European fingolimod SmPC. ${ }^{8-11}$ As stated in the SmPC, fingolimod is mainly used as a second-line DMT unless patients have highly active

Figure 3 Freedom from clinical disease activity during 36 months of fingolimod treatment

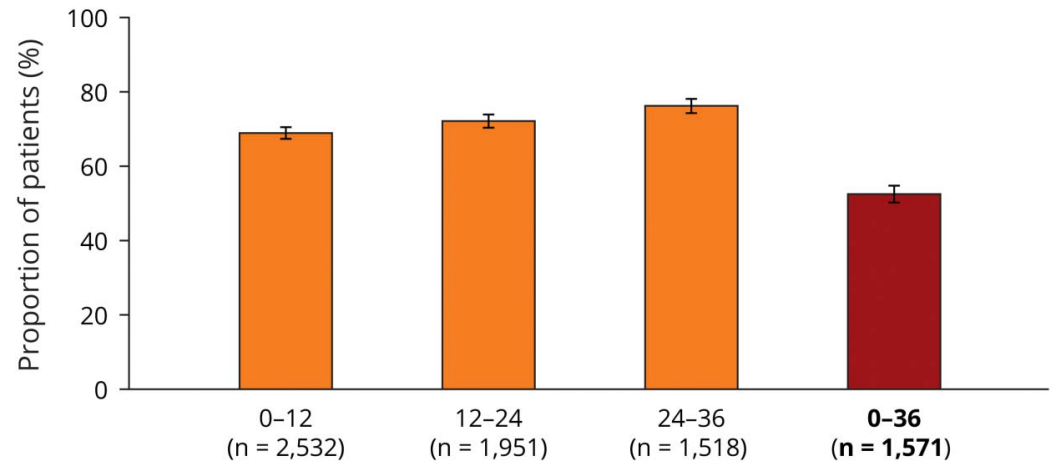

Follow-up period after fingolimod initiation (months)
Mean proportion of patients who were free from relapses and 6-month confirmed disability progression during each 12-month follow-up period and in the overall 36month follow-up period following fingolimod initiation. Error bars show $95 \% \mathrm{Cl}$. N = number of patients. Data for the 0-12-month period were taken from Ziemssen $\mathrm{T}$, Lang M, Tackenberg B et al. Clinical and demographic profile of patients receiving fingolimod in clinical practice in Germany and the benefit-risk profile of fingolimod after 1 year of treatment: initial results from the observational, noninterventional study PANGAEA. Neurotherapeutics 2018;15:190-199, with the permission of the copyright holders (authors). 
Table 1 Reasons for study discontinuation during 36 months of fingolimod treatment

\begin{tabular}{ll}
\hline Reason for discontinuation & $\begin{array}{l}\text { Number (\%) of times } \\
\text { a reason was given } \\
\left(\mathbf{N}=1,773^{\mathbf{a}}\right)\end{array}$ \\
\hline Patient decision & $493(27.8)$ \\
\hline AE & $437(24.6)$ \\
\hline $\begin{array}{l}\text { Lost to follow-up/switch of physician/switch } \\
\text { to other study }\end{array}$ & $325(18.3)$ \\
\hline Lack of effectiveness/disease progression & $224(12.6)$ \\
\hline Noncompliance of the patient & $86(4.9)$ \\
\hline Pregnancy/wish to become pregnant & $64(3.6)$ \\
\hline Switch to other therapy & $55(3.1)$ \\
\hline Physician's decision (not further classified) & $40(2.3)$ \\
\hline Screening failure/conversion to SPMS & $30(1.7)$ \\
\hline Other & $19(1.1)$ \\
\hline
\end{tabular}

Abbreviations: $\mathrm{AE}=$ adverse event; $\mathrm{N}=$ number of patients; SPMS = secondary progressive MS.

${ }^{a}$ Total number of reasons given by 1,436 patients who discontinued the study during PANGAEA; more than 1 reason could be given at any time.

disease, in which case fingolimod can be used as a first-line treatment. ${ }^{8}$ Consistently, approximately $94 \%$ of patients in PANGAEA received previous DMTs before initiating fingolimod, whereas in the pivotal phase 3 RCTs, $24 \%-59 \%$ of patients received fingolimod first line. ${ }^{9-11}$ This is despite patients entering PANGAEA having similar mean ages and disease durations, and more active disease at baseline than at enrollment into these RCTs. ${ }^{12,13}$ In line with previous observations, the majority of patients had received injectable DMTs (interferons and glatiramer acetate) before initiating fingolimod in PANGAEA.

To improve clinical outcomes and to achieve treatment goals, it is important that DMTs are associated with high levels of persistence. In the present study, in patients who received fingolimod for the first time, therapy continuation was high over the 36-month follow-up period. The therapy continuation rates in the present study were in line with, or higher than, those reported during the core phase of the pivotal fingolimod RCTs $(68 \%-87 \%)^{10,11}$ or in real-world studies $(73 \%-89 \%){ }^{16,17}$ Importantly, annual therapy continuation rates were similar in each 12-month period of follow-up, suggesting that patients who fare well on fingolimod in the first year are likely to continue receiving therapy. In the present study, over the 36-month followup period, the major reasons for fingolimod discontinuation were patient decision and AEs. This is consistent with reasons for discontinuation from other real-world studies of fingolimod. ${ }^{18-20}$

As part of PANGAEA, patients received fingolimod in accordance with its SmPC, and, therefore, results are likely to be generalizable to the population of patients receiving treatment in routine clinical practice. In the present analysis, ARRs continued to decrease in each year of fingolimod treatment and the proportion of patients remaining free from relapses increased. The effect of fingolimod on relapse outcomes was most pronounced after 24-36 months, which suggests that its benefits are sustained and may increase with duration of treatment. However, the accrual of effectiveness over time may also be attributed to responder bias, in which patients for whom fingolimod was effective would be most likely to continue receiving this treatment.

For disability outcomes, EDSS scores remained stable during the 36-month follow-up period, and only a small proportion of patients $(<10 \%)$ experienced confirmed disability worsening during any 12-month follow-up period. In addition, improvements in EDSS scores were observed in an increasing proportion of patients in each 12-month follow-up period. The long-term importance of preventing disability worsening is highlighted by a recent study, in which patients with confirmed disability worsening over 10 years had greater levels of neurodegeneration, as measured by serial MRI scans, than patients with stable levels of disability. ${ }^{21}$ Neurodegeneration is linked to physical and cognitive disability, and slowing it has long-term prognostic benefits. ${ }^{21}$

Increasingly, combined disease activity assessments are being used to monitor the overall effectiveness of DMTs, rather than measuring outcomes in isolation. ${ }^{22}$ In the present analysis, patients were assessed based on to their freedom from clinical disease activity (relapses and disability). The proportion of patients free from both relapses and confirmed disability worsening increased in each 12-month follow-up period, and over the 36-month follow-up period, over half of patients were free from clinical disease activity. Importantly, as shown here and in a previously published interim analysis of data from PANGAEA, the effectiveness of fingolimod is apparent within 12 months of fingolimod initiation, which indicates that its sustained benefits take effect early. ${ }^{12}$ This combined assessment does not take into account MRI measures of disease activity, which provide insight into the pathologic processes underlying clinical disease activity. An ongoing German study, PANGAEA 2.0, aims to assess treatment outcomes in accordance with clinical and MRI measures of disease activity. ${ }^{23}$

Patients receiving fingolimod in routine clinical practice are likely to have comorbidities and be receiving concomitant medications, ${ }^{12}$ which may predispose them to certain AEs during fingolimod treatment. Furthermore, some AEs may only be observed after an extended duration of treatment. ${ }^{24-26}$ In the present analysis, safety data were systematically assessed. AEs were reported by up to $23.4 \%$ patients during any 12-month follow-up period. These overall rates of AEs were lower than those described in the core periods of the pivotal fingolimod phase 3 RCTs and in 2 recent real-world studies, in which AEs were reported by $35.4 \%{ }^{27}$ and $47.8 \%{ }^{28}$ of patients. SAEs were reported by up to $3.9 \%$ of patients 
Table 2 AEs of special interest during 36 months of fingolimod treatment

\begin{tabular}{|c|c|c|c|c|c|}
\hline \multirow[b]{2}{*}{ System } & \multirow[b]{2}{*}{ Preferred term } & \multicolumn{4}{|c|}{ No. of patients, $n(\%)$} \\
\hline & & $\begin{array}{l}0-12 \text { months, } \\
\mathrm{n}=1,379(100 \%)\end{array}$ & $\begin{array}{l}12-24 \text { months, } \\
\mathrm{n}=928(100 \%)\end{array}$ & $\begin{array}{l}24-36 \text { months, } \\
n=722(100 \%)\end{array}$ & $\begin{array}{l}\text { 0-36 months, } \\
\mathrm{n}=2,565(100 \%)\end{array}$ \\
\hline Cardiac events & Hypertension & $31(2.2 \%)$ & $11(1.2 \%)$ & $7(1.0 \%)$ & $53(2.1 \%)$ \\
\hline \multirow[t]{3}{*}{ Infections } & Herpes zoster & $4(0.3 \%)$ & $4(0.4 \%)$ & $4(0.6 \%)$ & $10(0.4 \%)$ \\
\hline & Progressive multifocal leukoencephalopathy & 0 & 0 & 0 & 0 \\
\hline & Meningitis, cryptococcal & 0 & 0 & 0 & 0 \\
\hline \multirow[t]{3}{*}{ Leukopenia $^{a}$} & Lymphopenia & $2(0.1 \%)$ & $1(0.1 \%)$ & $1(0.1 \%)$ & $2(0.1 \%)$ \\
\hline & Leukopenia & $1(0.1 \%)$ & 0 & $2(0.3 \%)$ & $2(0.1 \%)$ \\
\hline & White blood cell count decreased & 0 & 0 & $1(0.1 \%)$ & $2(0.1 \%)$ \\
\hline \multirow[t]{2}{*}{$\begin{array}{l}\text { Diseases of the } \\
\text { nervous system }\end{array}$} & $\begin{array}{l}\text { Posterior reversible encephalopathy } \\
\text { syndrome }\end{array}$ & 0 & 0 & 0 & 0 \\
\hline & Acute disseminated encephalomyelitis & 0 & 0 & 0 & 0 \\
\hline \multirow[t]{2}{*}{ Hepatic enzymes } & Hepatic enzyme level increased & $27(2.0 \%)$ & $18(1.9 \%)$ & $15(2.1 \%)$ & $52(2.0 \%)$ \\
\hline & Alanine aminotransferase level increased & $9(0.7 \%)$ & $6(0.6 \%)$ & $5(0.7 \%)$ & $18(0.7 \%)$ \\
\hline Eye disorder & Macular edema & 0 & 0 & 0 & 0 \\
\hline \multirow[t]{3}{*}{ Neoplasms } & Thyroid neoplasm & 0 & $1(0.1 \%)$ & 0 & 0 \\
\hline & Benign breast neoplasm & 0 & 0 & $1(0.1 \%)$ & $1(0.0 \%)$ \\
\hline & Benign neoplasm & 0 & 0 & $1(0.1 \%)$ & $1(0.0 \%)$ \\
\hline Lymphoma & & 0 & 0 & 0 & 0 \\
\hline Pregnancy & Abortion, induced & $1(0.1 \%)$ & 0 & $1(0.1 \%)$ & $1(0.0 \%)$ \\
\hline
\end{tabular}

Abbreviations: $\mathrm{AE}$ = adverse event; $\mathrm{N}(\mathrm{n})$ = number of patients; $\mathrm{SAE}=$ serious $\mathrm{AE} ; \mathrm{SmPC}=$ summary of product characteristics.

An AE was defined as any unfavorable change in a patient's pretreatment condition regardless of a potential relationship to treatment and irrespective of whether medication was taken as indicated. SAEs were defined as lethal or life-threatening events, hospitalizations, events leading to major incapacity, persistent or significant disability or incapacity, congenital anomaly or birth defect, and events that were otherwise deemed to be medically significant (e.g., abnormal laboratory values or test results). At every visit, the treating neurologist documented the occurrence of AEs and SAEs. For each event, the type, time of first occurrence, duration, intensity, and causal relationship to the therapy were documented.

a For patients enrolled in PANGAEA who had a confirmed absolute lymphocyte count below $0.2 \times 10^{9} / \mathrm{L}$ after treatment with fingolimod, treatment was interrupted until recovery as per the SmPC for fingolimod.

during any 12-month follow-up period in the present analysis, which is consistent with that reported in the literature (2.9\%). ${ }^{27}$ The highest proportion of patients experienced AEs and SAEs in the 0-12-month period, suggesting that most events occurred early during fingolimod treatment. AEs of special interest that occurred with the highest frequency in each 12-month period and in the overall 36-month period were hypertension, increased hepatic enzyme levels, and increased alanine aminotransferase levels. The reported AEs of special interest are consistent with, but occur at a lower frequency than, those reported over 12 and 24 months in the pivotal fingolimod RCTs and in other real-world studies. ${ }^{9-11,27-29}$

A strength of this analysis is that it presents the largest realworld data set for a population of patients receiving fingolimod in accordance with its SmPC and being managed as part of routine clinical practice at neurologic centers across Germany. This study has now collected data systematically for a longer period than the core phase of the pivotal phase 3 RCTs and demonstrates the sustained favorable benefit-risk profile of fingolimod. A limitation of this analysis is that MRI data were not consistently collected during the study, and therefore, it is not possible to assess composite disease end points such as no evidence of disease activity. Furthermore, data collected reflect the use of fingolimod within a German population of patients with MS and may not be generalizable to other countries, particularly those in which the use of fingolimod is restricted or the treatment label is different. For example, in countries where fingolimod is mainly used as a first-line therapy, its observed effectiveness may differ from that in countries, such as Germany, where fingolimod is mainly used as a second-line therapy. In this study, it is not possible to determine whether patients have used DMTs as prescribed. The present study lacks a comparator arm, and safety data were not collected in a protocol-driven way, as would be the case for an RCT; however, the findings can be considered in the context of other real-world studies.

Owing to the chronic, incurable nature of MS, patients require lifelong treatment with DMTs. It is therefore important that 
patients are treated early with DMTs that have sustained effectiveness coupled with a manageable safety profile; this is likely to lead to high treatment persistence. Avoiding relapses and disability worsening is associated with improved healthrelated quality of life and reduced health care costs and resource use. ${ }^{30-34}$ Furthermore, sustained reductions in disease activity are likely to be associated with favorable clinical outcomes. ${ }^{3}$ This study highlights the potential of fingolimod as a DMT for the long-term management of patients with RMS.

\section{Acknowledgment}

The PANGAEA study group assisted in the collection of data and provided technical support.

\section{Study funding}

The study was sponsored by Novartis Pharma GmbH.

\section{Disclosure}

T. Ziemssen served on the scientific advisory boards of Bayer, Biogen, Novartis, Merck Serono, Teva, Genzyme, Roche, and Celgene; received speaker honoraria from Bayer, Biogen, Sanofi Genzyme, Celgene, Roche, Novartis, Teva, Almirall, and Merck; served as section editor of BMC Neurology; received research support from Biogen, Sanofi Genzyme, Novartis, and Teva; and served as an expert witness for glatiramer acetate. M. Land reports no disclosures. B. Tackenberg served on the scientific advisory boards of Biogen, Bayer Healthcare, Novartis Germany, Merck Serono Germany, Octapharma Germany, CSL Behring Germany, GRIFOLS Germany, Alexion, Celgene, and Sanofi Genzyme; received speaker honoraria from Biogen, Bayer, Novartis, Merck Serono, Octapharma, CSL Behring, Grifols, Alexion, Celgene, and Sanofi Genzyme; consulted for Biogen, Bayer Healthcare, Novartis, Merck Serono, Octapharma, CSL Behring, Grifols, Alexion, Celgene, and Sanofi Genzyme; and received research support from Bayer, Biogen Idec, Novartis, Sanofi-Aventis, Marburg University Trust, Förderverein Neurologie, German Myasthenia Gravis Society, and German Society of Neurology. S. Schmidt served on the scientific advisory boards of Novartis, Merck Serono, Bayer Vital, Biogen, Genzyme, and Teva; received travel funding and/or speaker honoraria from Novartis, Merck Serono, Bayer Vital Biogen, Genzyme, and Teva; and received research support from Bayer Vital. $\mathrm{H}$. Albrect served on the scientific advisory boards of Merck, Biogen, Sanofi-Aventis, Novartis, and Mylan and received travel funding and/or speaker honoraria from Merck, Novartis, Biogen, and Celgene. L. Klotz served on the scientific advisory boards of Genzyme, Novartis, Biogen, Roche, Merck, and CSL Behring; received travel funding and speaker honoraria from Novartis, Merck Serono, Biogen, Roche, Genzyme, and CSL Behring; and received research support from Novartis, Biogen, CRC, Federal Ministry of Education and Research. J. Haas received honorarium from Biogen Idec, Merck Serono, Bayer Schering, Teva-Aventis, Novartis, and Octapharma. C. Lassek served on the scientific advisory boards of and received travel funding/ speaker honoraria and research support from Merck
Serono, Genzyme-Sanofi, Novartis, Roche, and Biogen. C.A.-M Couto and J.A. Findlay have been employed by Oxford PharmaGenesis. C. Cornelissen has been employed by Siemens Healthcare and Novartis. Disclosures available: Neurology.org/NN.

\section{Publication history}

Received by Neurology: Neuroimmunology \& Neuroinflammation July 27, 2018. Accepted in final form January 8, 2019.

Appendix 1 Author contributions

\begin{tabular}{llll}
\hline Name & Location & Role & Contribution \\
\hline $\begin{array}{l}\text { T. Ziemssen, } \\
\text { MD, PhD }\end{array}$ & $\begin{array}{l}\text { University of } \\
\text { Technology, } \\
\text { Dresden }\end{array}$ & Author & $\begin{array}{l}\text { Study design; study } \\
\text { recruitment; } \\
\text { acquisition and } \\
\text { interpretation of data; } \\
\text { and critical revision of } \\
\text { the manuscript }\end{array}$ \\
\hline M. Lang, MD & $\begin{array}{lll}\text { NeuroPoint } \\
\text { Patient Academy } \\
\text { and Neurological } \\
\text { Practice, Ulm }\end{array}$ & Author & $\begin{array}{l}\text { Study recruitment; } \\
\text { acquisition and } \\
\text { interpretation of data; } \\
\text { and critical revision of } \\
\text { the manuscript }\end{array}$ \\
& & &
\end{tabular}

\begin{tabular}{llll}
\hline $\begin{array}{l}\text { B. Tackenberg, } \\
\text { MD }\end{array}$ & $\begin{array}{l}\text { Philipps- } \\
\text { University, } \\
\text { Marburg }\end{array}$ & Author & $\begin{array}{l}\text { Study recruitment; } \\
\text { acquisition and } \\
\text { interpretation of data; } \\
\text { and critical revision of } \\
\text { the manuscript }\end{array}$ \\
\hline S. Schmidt, MD & $\begin{array}{l}\text { Bonn } \\
\text { Neurological } \\
\text { Practice, Bonn }\end{array}$ & Author & $\begin{array}{l}\text { Study recruitment; } \\
\text { acquisition and } \\
\text { interpretation of data; } \\
\text { and critical revision of } \\
\text { the manuscript }\end{array}$
\end{tabular}

\begin{tabular}{|c|c|c|c|}
\hline $\begin{array}{l}\text { H. Albrecht, } \\
\text { MD }\end{array}$ & $\begin{array}{l}\text { Neurologic } \\
\text { Practice, Munich }\end{array}$ & Author & $\begin{array}{l}\text { Study recruitment; } \\
\text { acquisition and } \\
\text { interpretation of data; } \\
\text { and critical revision of } \\
\text { the manuscript }\end{array}$ \\
\hline
\end{tabular}

\begin{tabular}{|c|c|c|c|}
\hline L. Klotz, MD & $\begin{array}{l}\text { University } \\
\text { Hospital Münster, } \\
\text { Münster }\end{array}$ & Author & $\begin{array}{l}\text { Study recruitment; } \\
\text { acquisition and } \\
\text { interpretation of data; } \\
\text { and critical revision of } \\
\text { the manuscript }\end{array}$ \\
\hline J. Haas, MD & $\begin{array}{l}\text { Jewish Hospital } \\
\text { Berlin, Berlin }\end{array}$ & Author & $\begin{array}{l}\text { Study recruitment; } \\
\text { acquisition and } \\
\text { interpretation of data; } \\
\text { and critical revision of } \\
\text { the manuscript }\end{array}$ \\
\hline C. Lassek, MD & $\begin{array}{l}\text { Kassel and } \\
\text { Vellmar } \\
\text { Neurology } \\
\text { Practice, Vellmar }\end{array}$ & Author & $\begin{array}{l}\text { Study recruitment; } \\
\text { acquisition and } \\
\text { interpretation of data; } \\
\text { and critical revision of } \\
\text { the manuscript }\end{array}$ \\
\hline $\begin{array}{l}\text { C. A. Marie- } \\
\text { Couto, DPhil }\end{array}$ & $\begin{array}{l}\text { Oxford } \\
\text { PharmaGenesis, } \\
\text { UK }\end{array}$ & Author & $\begin{array}{l}\text { Drafting and critical } \\
\text { revision of the } \\
\text { manuscript }\end{array}$ \\
\hline $\begin{array}{l}\text { J.A. Findlay, } \\
\text { PhD }\end{array}$ & $\begin{array}{l}\text { Oxford } \\
\text { PharmaGenesis, } \\
\text { UK }\end{array}$ & Author & $\begin{array}{l}\text { Drafting and critical } \\
\text { revision of the } \\
\text { manuscript }\end{array}$ \\
\hline $\begin{array}{l}\text { C. Cornelissen, } \\
\text { PhD }\end{array}$ & $\begin{array}{l}\text { Novartis Pharma } \\
\text { GmbH, } \\
\text { Nuremberg (at the } \\
\text { time of this study) }\end{array}$ & Author & $\begin{array}{l}\text { Study design; } \\
\text { interpretation of data; } \\
\text { and critical revision of } \\
\text { the manuscript }\end{array}$ \\
\hline
\end{tabular}


Appendix 2 Coinvestigators

\begin{tabular}{llll}
\hline Name & Location & Role & Contribution \\
\hline $\begin{array}{l}\text { H-P Duerr, } \\
\text { PhD }\end{array}$ & Numerus Ltd. & $\begin{array}{l}\text { Principal } \\
\text { epidemiologist }\end{array}$ & $\begin{array}{l}\text { Statistical } \\
\text { analysis }\end{array}$ \\
\hline H-J Schwarz & $\begin{array}{l}\text { Kantar Health } \\
\text { GmbH }\end{array}$ & $\begin{array}{l}\text { Senior professional } \\
\text { biostatistician }\end{array}$ & $\begin{array}{l}\text { Statistical } \\
\text { analysis }\end{array}$ \\
\hline
\end{tabular}

\section{References}

1. Trojano $\mathrm{M}$, Tintore $\mathrm{M}$, Montalban $\mathrm{X}$, et al. Treatment decisions in multiple sclerosis—insights from real-world observational studies. Nat Rev Neurol 2017;13: $105-118$.

2. Ziemssen T, De Stefano N, Pia Sormani M, Van Wijmeersch B, Wiendl H, Kieseier BC. Optimizing therapy early in multiple sclerosis: an evidence-based view. Mult Scler Relat Disord 2015;4:460-469.

3. Ziemssen T, Derfuss T, de Stefano N, et al. Optimizing treatment success in multiple sclerosis. J Neurol 2016;263:1053-1065.

4. Ziemssen $\mathrm{T}$, Hillert J, Butzkueven $\mathrm{H}$. The importance of collecting structured clinical information on multiple sclerosis. BMC Med 2016;14:81.

5. ABPI. Guidance-demonstrating value with real world data: a practical guide. 2011. Available at: abpi.org.uk/media/1591/2011-06-13-abpi-guidance-demonstratingvalue-with-real-world-data.pdf. Accessed December 20, 2017.

6. Ziemssen T, Kern R, Thomas K. Multiple sclerosis: clinical profiling and data collection as prerequisite for personalized medicine approach. BMC Neurol 2016;16: 124.

7. Capkun G, Lahoz R, Verdun E, et al. Expanding the use of administrative claims databases in conducting clinical real-world evidence studies in multiple sclerosis. Curr Med Res Opin 2015;31:1029-1039.

8. Agency EM. Gilenya EPAR Product Information. 2014. Available at: ema.europa.eu/ docs/en_GB/document_library/EPAR_-_Product_Information/human/002202/ WC500104528.pdf. Accessed December 20, 2017.

9. Calabresi PA, Radue EW, Goodin D, et al. Safety and efficacy of fingolimod in patients with relapsing-remitting multiple sclerosis (FREEDOMS II): a double-blind, randomised, placebo-controlled, phase 3 trial. Lancet Neurol 2014;13:545-556.

10. Cohen JA, Barkhof F, Comi G, et al. Oral fingolimod or intramuscular interferon for relapsing multiple sclerosis. N Engl J Med 2010;362:402-415.

11. Kappos L, Radue EW, O'Connor P, et al. A placebo-controlled trial of oral fingolimod in relapsing multiple sclerosis. N Engl J Med 2010;362:387-401.

12. Ziemssen $\mathrm{T}$, Lang $\mathrm{M}$, Tackenberg B, et al. Clinical and demographic profile of patients receiving fingolimod in clinical practice in Germany and the benefit-risk profile of fingolimod after 1 year of treatment: initial results from the observational, noninterventional study PANGAEA. Neurotherapeutics 2018;15:190-199.

13. Ziemssen $\mathrm{T}$, Kern R, Cornelissen C. The PANGAEA study design-a prospective, multicenter, non-interventional, long-term study on fingolimod for the treatment of multiple sclerosis in daily practice. BMC Neurol 2015;15:93.

14. Becker V, Heeschen V, Schuh K, Schieb H, Ziemssen T. Patient satisfaction and healthcare services in specialized multiple sclerosis centres in Germany. Ther Adv Neurol Disord 2018;11:1756285617748845.
15. Ziemssen T, Medin J, Couto CAM, Mitchell CR. Multiple sclerosis in the real world: a systematic review of fingolimod as a case study. Autoimmun Rev 2017; 16:355-376.

16. Al-Hashel J, Ahmed SF, Behbehani R, Alroughani R. Real-world use of fingolimod in patients with relapsing remitting multiple sclerosis: a retrospective study using the national multiple sclerosis registry in Kuwait. CNS Drugs 2014;28:817-824.

17. Bergvall N, Lahoz R, Reynolds T, Korn JR. Healthcare resource use and relapses with fingolimod versus natalizumab for treating multiple sclerosis: a retrospective US claims database analysis. Curr Med Res Opin 2014;30:1461-1471.

18. Frisell T, Forsberg L, Nordin N, et al. Comparative analysis of first-year fingolimod and natalizumab drug discontinuation among Swedish patients with multiple sclerosis. Mult Scler 2016;22:85-93.

19. Lapierre Y, O'Connor P, Devonshire V, et al. Canadian experience with fingolimod: adherence to treatment and monitoring. Can J Neurol Sci 2016;43:278-283.

20. Vollmer B, Nair KV, Sillau SH, Corboy J, Vollmer T, Alvarez E. Comparison of fingolimod and dimethyl fumarate in the treatment of multiple sclerosis: Two-year experience. Mult Scler J Exp Transl Clin 2017;3:2055217317725102.

21. Zivadinov R, Uher T, Hagemeier J, et al. A serial 10-year follow-up study of brain atrophy and disability progression in RRMS patients. Mult Scler 2016;22: 1709-1718.

22. Kappos L, De Stefano N, Freedman MS, et al. Inclusion of brain volume loss in a revised measure of 'no evidence of disease activity' (NEDA-4) in relapsing-remitting multiple sclerosis. Mult Scler 2016;22:1297-1305.

23. Ziemssen $\mathrm{T}$, Kern R, Cornelissen C. Study design of PANGAEA 2.0, a noninterventional study on RRMS patients to be switched to fingolimod. BMC Neurol 2016;16:129.

24. Cohen JA, Kappos L, Selmaj K, et al. Long-term safety and effectiveness of fingolimod: 7 year data from the LONGTERMS study. Mult Scler 2015;21:280.

25. Kappos L, Cohen J, Collins W, et al. Fingolimod in relapsing multiple sclerosis: an integrated analysis of safety findings. Mult Scler Relat Disord 2014;3:494-504.

26. Kappos L, O'Connor P, Radue EW, et al. Long-term effects of fingolimod in multiple sclerosis: the randomized FREEDOMS extension trial. Neurology 2015;84 1582-1591.

27. Laroni A, Brogi D, Brescia Morra V, et al. Safety and tolerability of fingolimod in patients with relapsing-remitting multiple sclerosis: results of an open-label clinical trial in Italy. Neurol Sci 2017;38:53-59.

28. Izquierdo G, Damas F, Paramo MD, Ruiz-Pena JL, Navarro G. The real-world effectiveness and safety of fingolimod in relapsing-remitting multiple sclerosis patients: An observational study. PLoS One 2017;12:e0176174.

29. Guarnera C, Bramanti P, Mazzon E. Comparison of efficacy and safety of oral agents for the treatment of relapsing-remitting multiple sclerosis. Drug Des Devel Ther 2017;11:2193-2207.

30. Derwenskus J. Current disease-modifying treatment of multiple sclerosis. Mt Sinai J Med 2011;78:161-175

31. Flachenecker P, Kobelt G, Berg J, Capsa D, Gannedahl M. European Multiple Sclerosis Platform. New insights into the burden and costs of multiple sclerosis in Europe: results for Germany. Mult Scler 2017;23:78-90.

32. Kobelt G, Berg J, Lindgren P, Fredrikson S, Jonsson B. Costs and quality of life of patients with multiple sclerosis in Europe. J Neurol Neurosurg Psychiatry 2006;77: 918-926.

33. Kobelt G, Thompson A, Berg J, et al. New insights into the burden and costs of multiple sclerosis in Europe. Mult Scler 2017;23:1123-1136.

34. Sobocki P, Pugliatti M, Lauer K, Kobelt G. Estimation of the cost of MS in Europe: extrapolations from a multinational cost study. Mult Scler 2007;13:1054-1064. 


\title{
Neurology \\ Neuroimmunology \& Neuroinflammation
}

\author{
Real-world persistence and benefit-risk profile of fingolimod over 36 months in \\ Germany \\ Tjalf Ziemssen, Michael Lang, Björn Tackenberg, et al. \\ Neurol Neuroimmunol Neuroinflamm 2019;6; \\ DOI 10.1212/NXI.0000000000000548
}

This information is current as of March 7, 2019

\section{Updated Information \& \\ Services}

References

Subspecialty Collections

Permissions \& Licensing

Reprints including high resolution figures, can be found at:

http://nn.neurology.org/content/6/3/e548.full.html

This article cites 32 articles, 1 of which you can access for free at: http://nn.neurology.org/content/6/3/e548.full.html\#\#ref-list-1

This article, along with others on similar topics, appears in the following collection(s):

Clinical trials Observational study (Cohort, Case control)

http://nn.neurology.org//cgi/collection/clinical_trials_observational_stu dy_cohort_case_control

Multiple sclerosis

http://nn.neurology.org//cgi/collection/multiple_sclerosis

Information about reproducing this article in parts (figures,tables) or in its entirety can be found online at:

http://nn.neurology.org/misc/about.xhtml\#permissions

Information about ordering reprints can be found online:

http://nn.neurology.org/misc/addir.xhtml\#reprintsus

Neurol Neuroimmunol Neuroinflamm is an official journal of the American Academy of Neurology.

Published since April 2014, it is an open-access, online-only, continuous publication journal. Copyright

Copyright $@ 2019$ The Author(s). Published by Wolters Kluwer Health, Inc. on behalf of the American

Academy of Neurology.. All rights reserved. Online ISSN: 2332-7812.

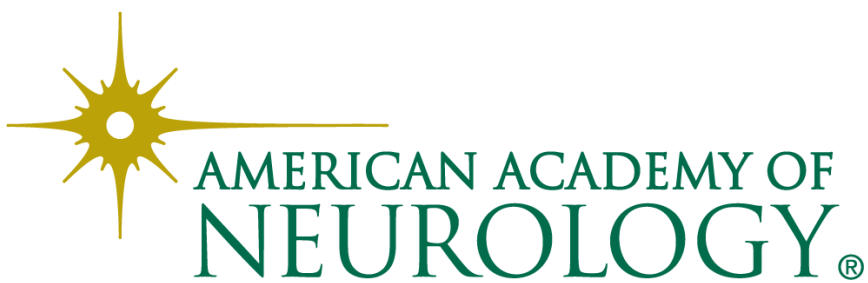

